\title{
LUCICAT Model as a river flow forecasting tool: an experiment with Fitzroy River catchment of Western Australia
}

\author{
$\underline{\text { S.A. Islam }}^{\mathrm{a} b}{ }^{\mathrm{b}}$, A.H.M.F. Anwar ${ }^{\mathrm{a}}$, G. Ezzy ${ }^{\mathrm{b}}$ and M. Bari ${ }^{\mathrm{b}}$ \\ ${ }^{a}$ Department of Civil Engineering, School of Civil and Mechanical Engineering, Curtin University, Western \\ Australia \\ ${ }^{b}$ Climate and Water Division, Bureau of Meteorology, Western Australia \\ Email: s.islam@bom.gov.au
}

\begin{abstract}
Early warnings of river flow, particularly high flow, allow individuals, communities and industries to respond in an appropriate manner to reduce the probability of suffering, personal injury, death and economic loss. To increase the lead time of river forecasting, major river forecasting centers across the world are using numerical weather predictions for continuous river flow forecasting. Low flow forecasting is also important to many stakeholders like water resources managers and farmers. The Land Use Change Incorporated Catchment (LUCICAT) model is a distributed lumped conceptual model which is widely used for water resources assessment in most of the Western Australian catchments and few eastern state catchments. This study aims at investigating LUCICAT model's potential in continuous river flow forecasting. The experiment is carried out in Fitzroy River catchment of Western Australia for simulating both high and low flow in hourly time step with an emphasis towards high flow. The model consists of two components: (a) the daily Water Balance Model (WBM) and (b) the Flood module. The daily WBM was calibrated for the period of 1961-2010 using observed daily stream flow data at 11 gauging stations against a set of calibration criteria which were (i) joint plot of observed and simulated daily flow series, (ii) scatter plot of monthly and annual flow, (iii) flow-period Error Index, (iv) Nash-Sutcliffe Efficiency, (v) Explained variance, (vi) Correlation Coefficient, (vii) overall water balance and (viii) flow duration curves. The Flood module was calibrated for 2006 flow event using observed hourly discharge and stage height data. The Flood module takes catchment initial condition from the daily WBM at a particular date from which the Flood module start running in hourly time step. For calibrating the Flood module, calibrated set of parameter from the daily WBM were taken and three parameters were adjusted which were (i) Dry water store soil moisture exponent, (ii) Wet water store soil moisture exponent and (iii) Lateral conductivity wet store (mm/day). Six separate flow events have been simulated in hourly time step to test following three hypotheses: (i) a single set of parameters is valid for the whole catchment, (ii) a single set of parameters is valid for different flood events, and (iii) no change of parameter is required during operational prediction. Findings suggest that the hypotheses are valid and the model has fairly good potential in simulating continuous river flow, both high and low flow. Hence, once the model is calibrated for a particular catchment, it can be used for water resources assessment and continuous river flow forecasting.
\end{abstract}

Keywords: $\quad$ LUCICAT, Flood, Fitzroy River catchment, Continuous flow, Forecasting 
Islam et al., LUCICAT Model as a river flow forecasting tool: an experiment with Fitzroy River catchment of Western Australia

\section{INTRODUCTION}

Across the world, need for improvement in flood forecasting along with flood protection and awareness is rising and becoming a political agenda during the last decades (Cloke and Pappenberger, 2009).The importance of river flow forecasting, particularly high flow, has gained more ground in recent time in Australia due to the wide spread extreme flood events during 2010-2012 and early 2013. After more than a decade of drought, the flood events in recent time has brought to surface the urgency of accurate and timely forecasts of river flow in Australia for water resources management and disaster mitigation. Early warnings (i.e. timely and reliable information) of river flow, particularly high flow, allow individuals, communities and industries to respond in an appropriate manner to reduce the probability of suffering, personal injury, death and economic loss. One of the key elements of an early warning system for providing warning (several days ahead or with sufficient lead time) is continuous river flow modeling (with hydrologic and hydraulic models) using probabilistic numerical rainfall forecasts, in addition to observed rainfall. The river flow produced using a single set of rainfall forecast poses significant uncertainty drawing a single set of trajectory of the likely flow scenarios. To address the uncertainty involved in a single deterministic forecast, operational and research flood forecasting systems around the world are more inclined towards multi-model ensemble forecast of river flow (Cloke and Pappenberger, 2009). This process involves a single or multiple hydrologic or hydraulic or a combination of models which takes ensemble of probabilistic rainfall from several numerical weather prediction models as input to simulate probabilistic river flow scenarios.

To carry out the experiment, Fitzroy River catchment of Western Australia has been selected. Though hydrology of the catchment is not well explored, limited work has been carried out. Late Holocene floods along the Fitzroy and Margaret rivers are investigated by Wohl et al. (1994) from sedimentary records. Taylor (2000) has reconstructed the paleo-climate record of the Fitzroy River through flood geomorphology. Ackland et al. (2012) examined flood monitoring at continental scale, considering the Fitzroy as one of the catchments in the study. To estimate flood plain inundation and flood discharge for the Fitzroy River catchment, Karim et al. (2011) carried out hydro-dynamic modeling in conjunction with remote sensing. The hydrological assessment of the Fitzroy alluvium is conducted by Lindsay and Commander (2005) for assessing ground water resources of the alluvium. Harrington et al. (2011) investigated surface watergroundwater interactions in the lower Fitzroy River from water resources point of view. This study is a step towards aiming a multi-model ensemble of continuous river flow forecast using probabilistic ensemble rainfall forecast. As first step, the main objective of this study is to investigate LUCICAT model's potential in continuous river flow forecasting through simulating flow at the gauging stations of Fitzroy River catchment. Emphasis has been given towards high flow so that the model can be used as a flood forecasting tool. Three hypotheses tested here to simulate hourly flow are: (i) a single set of model parameters is valid for the whole catchment, (ii) a single set of model parameters is valid for low and high flow and multiple flood events and (iii) no change of model parameters during operational prediction.

\section{THE FITZROY RIVER CATCHMENT}

The Fitzroy River catchment (area around $97,000 \mathrm{~km}^{2}$ ) is located in the south west part of the Kimberley region, North West of Western Australia (Figure 1). The north eastern half of the catchment is part of an ancient plateau with elevated exposed igneous and metamorphic rocks of the rugged King Leopold Range and Muller Range resulted from the tectonic uplifting of the Kimberley (CSIRO, 2009). The south western part of the catchment (downstream of Fitzroy Crossing) is overly the pericratonic Canning Basin with limited topographic reliefs. Elevation difference in the catchment is of around $1000 \mathrm{~m}$.

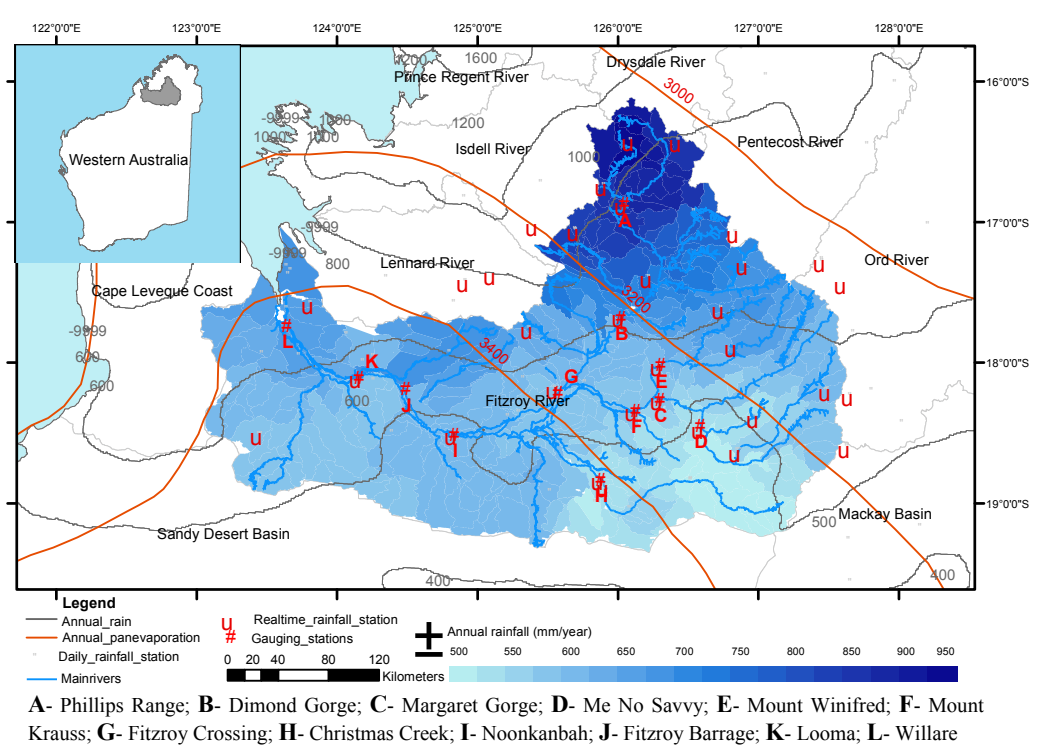

Figure 1. The Fitzroy River catchment of Western Australia. 
Islam et al., LUCICAT Model as a river flow forecasting tool: an experiment with Fitzroy River catchment of Western Australia

With many faults and folds, the plateau has eroded over time forming relatively flat rugged terrain with a thin layer of sandy soils. Hence, creeks and rivers of the north eastern part of the catchment respond to heavy rainfall sharply as high runoff flows quickly over the land surface due to rocky nature and steeper slope of the surface. As plains and hills have more soils, slopes are less steep, valleys are broader resulting runoff from rainfall are often less and slower and high flow spread out. Common form of vegetation in the catchment include tall-grass savannah woodland, curly spinfex savannah woodland, tree savannah, pindan, and tall and short bunch grass savannah. For tens of thousands of years, Aboriginal peoples have been living in the Fitzroy River catchment with low population densities (McConnel and O'Connar, 1997). Since the European migration began in 1890s, most of the land of the catchment came under pastoral leases.

The climate of the catchment is influenced by southern edge of the global monsoon system. The two dominant seasons of the catchment are a hot wet season from November to April followed by a warm dry winter. About $90 \%$ of annual rainfall occur during wet season (CSIRO, 2009) with high-intensity rainfall are from tropical cyclone and thunderstorm activities due to tropical weather system. Annual rainfall across the catchment varies considerably spatially from North to South, around $1000 \mathrm{~mm} / \mathrm{year}$ to $500 \mathrm{~mm} / \mathrm{year}$. Temporal variation of rainfall is also high, for example, the $10^{\text {th }}$ percentile and $90^{\text {th }}$ percentile of annual rainfall are $963 \mathrm{~mm} /$ year and $363 \mathrm{~mm} /$ year respectively (CSIRO, 2009). Annual potential evapotranspiration in the catchment varies from North East to South West, low to high with around $3000 \mathrm{~mm} / \mathrm{year}$ to 3600 $\mathrm{mm} /$ year (Figure 1). The rivers belong to a braided river system with numerous channels splits and re-joins in and around unstable bars and small islands, predominantly in the middle (Fitzroy Crossing) and lower part of the catchment. The channels vary enormously in depth and width with irregular and unstable river banks. During low flow period and dry season, some of the bars and islands are temporarily colonies of vegetation. Wet season flow carries sediment from upstream and deposit in channels forming pools and billabong while flood water flashes them away depositing sediments on flood plains. Around Fitzroy Crossing and downstream, flood water can extend to $15 \mathrm{~km}$ across the flood plain covering over 32,000 $\mathrm{km}^{2}$ (Karim et al., 2011).

\section{MODEL FRAMEWORK}

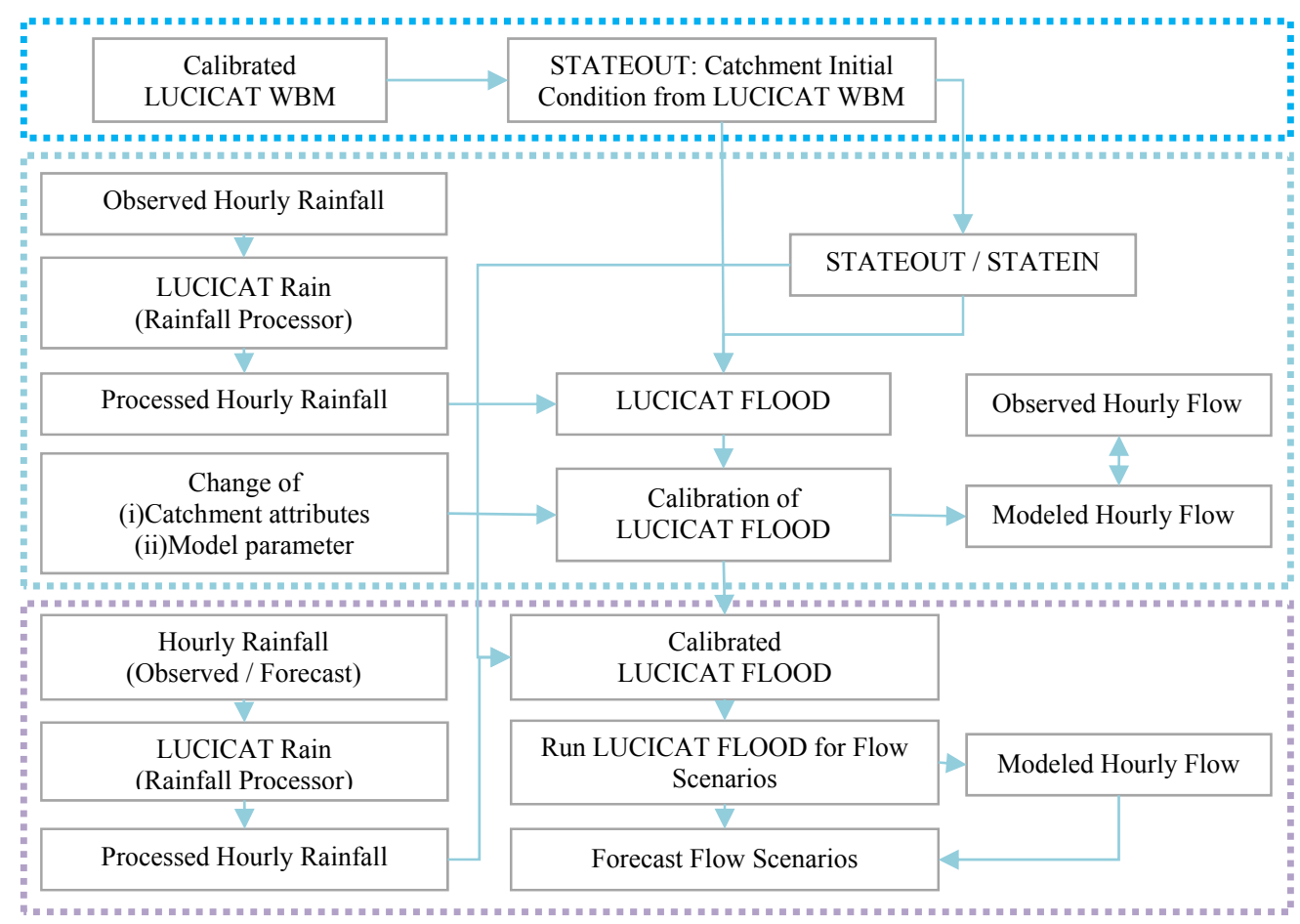

Figure 2. Conceptual framework used for the experiment of LUCICAT model calibration and prediction.

The conceptual framework for this experiment is shown in Figure 2, which consists of three modules: (i) calibration of LUCICAT Water Balance Model (WBM), (ii) calibration of LUCICAT Flood and (iii) running LUCICAT Flood for generating flow scenario. First, the LUCICAT WBM for the catchment is calibrated at the gauging stations using flow data in a daily time scale. Then WBM is run to dump catchment initial condition (STATEOUT) to a specific date from when LUCICAT Flood module starts running in an hourly time scale. The Flood module gets the catchment initial condition from the WBM as STSTEIN. The flood 
Islam et al., LUCICAT Model as a river flow forecasting tool: an experiment with Fitzroy River catchment of Western Australia

module is calibrated at the gauging stations using rainfall and flow data in hourly time scale. The calibrated Flood module with catchment initial condition from the WBM can be run with probabilistic forecast rainfall to develop flow scenario at gauging stations of the catchment.

\section{DATA AND METHODS}

The LUCICAT is a distributed lumped conceptual hydrologic model, which models a large catchment breaking into small Response Units (RU) (Bari and Smettem, 2003). The RUs are the basis for catchment attributes, land use, spatial distribution of rainfall and pan evaporation and other parameters. A channel network connects the RUs with nodes at start and joining of streams and at intersection of RU and streams. Flow from each RU is routed to downstream following Muskingum-Cunge routing scheme (Miller \& Cunge, 1975) and corresponding runoff generated flows through the channel network following the principles of open channel flow hydraulics. For the catchment under study, shape files for catchment attribute, channels network and nodes were prepared through processing Digital Elevation Model (DEM) for the catchment with ArcGIS Hydro tools, dividing the catchment into 337 RUs. With historical (1961-2010) daily rainfall data in and around the catchment, the daily Water Balance Model is calibrated at 11 gauging stations (Figure 1) comparing observed and modeled flow (1961-2010) against a set of criteria which are (i) joint plot of observed and simulated daily flow series, (ii) scatter plot of monthly and annual flow, (iii) flow-period Error Index, (iv) Nash-Sutcliffe Efficiency, (v) Explained variance, (vi) Correlation Coefficient, (vii) overall water balance and (viii) flow duration curves. The model has 29 parameters which are grouped as (i) estimated set of priori and (ii) variable set of eight physically meaningful parameters. Detail explanation of the parameters is available in Bari and Smettem (2003). The calibrated daily WBM was run to dump catchment initial condition at a particular date (23/01/2006), on set of starting higher flow (flood), as STATEOUT. Then LUCICAT Flood was run with hourly rainfall data available for a flood event in 2006 (23/01/2006$30 / 03 / 2006$ ) with catchment initial condition as STATEIN. The Flood module was calibrated for the event comparing observed and modeled hourly stage height through changing 3 hydrologic parameters taken form the calibrated daily WBM. The parameters changed for flood calibration are: (i) Dry water store soil moisture exponent, (ii) Wet water store soil moisture exponent and (iii) Lateral conductivity wet store ( $\mathrm{mm} / \mathrm{day}$ ). Thereafter, 6 flow events $(2000,2001,2002,2003$ and 2007 1\& 2) were simulated with the same set of models parameters used in calibration.

\section{MODEL CALIBRATION}

Model calibration consists of two steps: (i) calibration of the daily WBM and (ii) calibration of the Flood module. The steps are described below.

\subsection{LUCICAT Water Balance Model Calibration}

A summary of LUCICAT WBM calibrations at the gauging stations of the catchment are presented in Figure 3. Historical recorded daily rainfall data (Figure 1) in and around the catchment is used to generate daily flow at gauging stations. Through calibration process a single set of parameter has been derived for the whole catchment for simulating daily runoff and getting catchment initial conditions for input into Flood module. Overall water balance (E) from upstream to Fitzroy Crossing is within $\pm 4 \%$ but then on downstream modeled flow gradually exceeded the observed flow and at Willare it is almost double than observed flow (Figure 3). From upstream to Fitzroy Crossing, Nash-Sutcliffe Efficiency $\left(E^{2}\right)$ ranged from $0.33-0.63$ and from Fitzroy crossing to downstream it ranged from 0.20-0.28 (Figure 3). Calibration results indicate that the daily WBM is well calibrated for upper half (up to Fitzroy Crossing) of

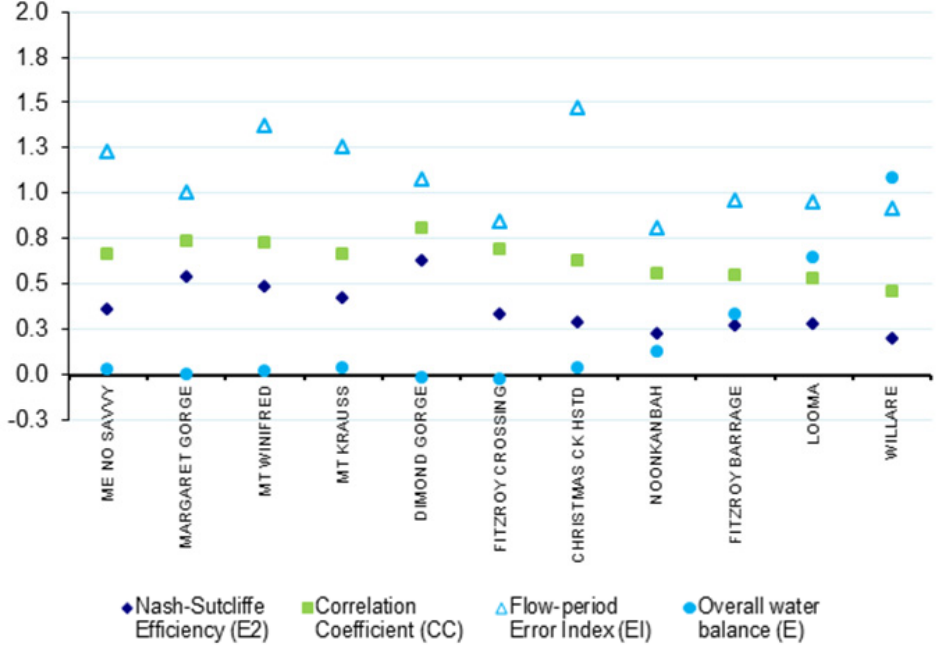

Figure 3. Calibration criteria used to calibrate the daily WBM for the experiment. 
Islam et al., LUCICAT Model as a river flow forecasting tool: an experiment with Fitzroy River catchment of Western Australia

the catchment. For downstream of Fitzroy Crossing, three major reason made calibration of the model very challenging, which are: (i) braided river system with multiple channels splitting and rejoining together along the course, (ii) very large flood plains which may extend up to $15 \mathrm{~km}$ covering over $32000 \mathrm{~km}^{2}$ during flood and (iii) very sparse rainfall network. Due to braided river system, measured flow at gauging stations at and downstream of Fitzroy Crossing does not represent the full flow, particularly during high flow. Therefore, for downstream of Fitzroy Crossing the model need to be used with caution.

\subsection{LUCICAT Flood Calibration}

The Flood module has been calibrated for part of 2006 wet season flow period. Catchment initial conditions has been dumped on 23/01/2006 as STATEOUT from daily WBM which subsequently taken as input into Flood module as STATEIN. The Flood module has been run with hourly rainfall data (see real time network in Figure. 1) to generate hourly runoff with the calibration set of parameter of calibrated daily WBM. First two parameters are unit independent while third parameter is read by the daily WBM in a daily time step. Hence, adjustments to the last parameter is made for the Flood module to suit hourly time steps (though the relationship is not linear). To adjust the travel time of flow at gauging stations, Manning's coefficient and channel width are modified across the catchment. Manning's coefficient has been adjusted based on catchment slope and channel width has been adjusted based on stream order. The modeled flow is compared with observed flow at all gauging stations and through a trial and error process, a set of parameter values are derived for the whole catchment for the Flood module. In Figure 4, hourly hydrographs with modeled and observed stage height are presented for three gauging stations at Dimond Gorge, Mount Krauss and Fitzroy Crossing. Dimond Gorge and Mount Krauss are two upstream gauging stations in two different rivers covering most of the upper half of the catchment which flow to gauge at Fitzroy Crossing though some flow by pass the gauge, particularly during high flow, due to braided river system. Hence, during calibration it is observed that model has a tendency to generate higher flow at Fitzroy Crossing.
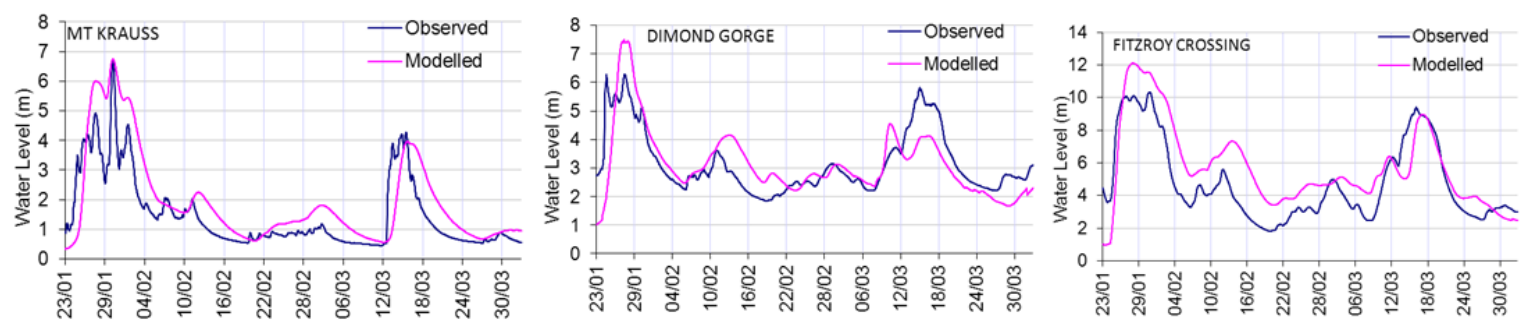

Figure 4. Hourly hydrograph at three gauging stations in the catchment during 2006.

\section{RESULTS AND DISCUSSION}

Three hypotheses (as mentioned in section 1) have been tested in this experiment through simulation of hourly flow at the gauging stations of the catchment. To simulate hourly flow, the model (WBM and Flood module) has been run for 2000, 2001, 2002, 2003 and 2007 ( 1 \& 2) high flow events (flood). All the events have been simulated using a single set of parameters corresponding to WBM and the Flood module which obtained through calibration of WBM and Flood module respectively. For each event the catchment initial condition is dumped at a particular date from the daily WBM and from that date the Flood module has been run in a prediction mode with hourly time step to simulate hourly flow. Hourly hydrograph for observed and simulated flow for 2002 event at three gauging stations are presented in Figure 5. The hydrographs indicate that the model can successfully simulate hourly flow, particularly high flow. It is also noted that the model can pick high flow event after quite a while (a month) later which is important from flood prediction point of view. For example, during 2002 event the Flood module has been run from 25/01/2002 with a low flow for around three weeks followed by a high flow period of around a week. The model also picked the recession limb of the hydrographs fairly well. For 2002 event, here the model has been run for about two month period. Hence, the model has shown promising results simulating hourly flow for more than a month period including low and high flow. Results from other events (for example 2001) depicts that the model is capable of simulating multiple picks i.e. high and low flow in succession. A summary of highest peak for observed and modeled flow for all the events at three gauging stations are presented in Figure 6 (a). This indicates that the model can simulate peak flow with an acceptable level of accuracy. As the Flood module has been run in prediction mode to simulate hourly flows for all the events with the same set of parameters obtained through calibration and kept same across the catchment, the three hypotheses set for this experiment are deemed to be valid. 
Islam et al., LUCICAT Model as a river flow forecasting tool: an experiment with Fitzroy River catchment of Western Australia

Overall, results indicate that the model has a tendency of simulating higher flow at Fitzroy Crossing with one or two day earlier than the observed peak period. The possible explanation is that from upstream of Fitzroy Crossing the rivers started to be braided and hence the recorded flow might represent only the flow through the main channel. During high flow like flood, a significant amount of water could bypass the gauge at Fitzroy Crossing. This is also evident from other literature (Karim et al., 2011) that during flood, the flood plain from upstream of Fitzroy Crossing to downstream extends about $15 \mathrm{~km}$. This reveals that it is quite reasonable to think that all the flow from upstream is not measured at Fitzroy Crossing, particularly during high flow when banks of the river over tops and flows bypass through other streams and floodplain contains significant portion of water. To understand the issue of measured and bypass flow at the gauging stations at Fitzroy Crossing and downstream, recorded annual flows at the gauging stations are plotted from 1998-2007 (Figure 6(b)). This plot indicates that recoded flows at downstream gauges are lower compared to upstream gauge, which is very much unlikely for a single steam channel. To explain further, river cross section at Willare is plotted which shows that the river is about $7 \mathrm{~km}$ wide with multiple channels (Figure 6 (c)). Hence, it is evident that the measured flow is part of the actual flow from upstream, particularly during high flow. Therefore, flow simulation with hydrologic modeling for downstream of Fitzroy Crossing appears to be challenging.
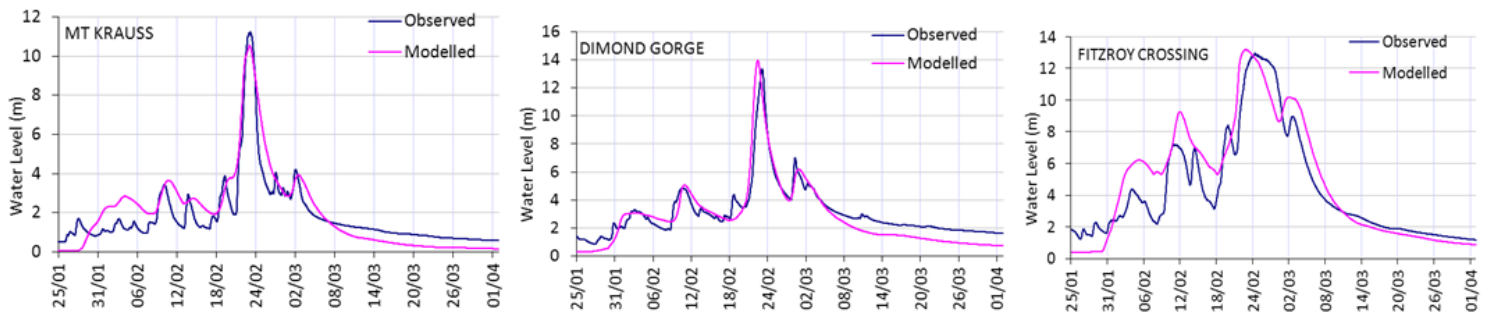

Figure 5. Hourly hydrographs at three gauging stations in the catchment during 2002.

Few other points need to be considered during hydrologic modeling for Fitzroy catchment particularly for simulating hourly flow. It is a very large catchment with limited and sparse rainfall network. Most of the real time rainfall stations are put in upper part of the catchment to predict flood at Fitzroy Crossing. In downstream of Fitzroy Crossing, the rainfall network is very limited along with braided river system. Also at Fitzroy Barrage, some water is diverted from the stream and data is not available on how much water is diverted and when. In addition, the catchment is located in remote northern part of Western Australia and maintaining the rainfall network is very costly and time consuming. For the events in this experiment, in an average 5-10 rainfall stations of the real time network shown in Figure 1 did not have recorded rainfall data as during the periods the stations were not functional. Furthermore, the floodplain around and downstream of Fitzroy Crossing is very wide and during high flow period it appears that along the stream water is everywhere forming an inland sea. These made hydrologic modeling difficult for upper half of the catchment and almost impossible for lower half of the catchment. Hence, basic knowledge of hydrology with catchment experience could be useful in predicting flow for lower half of the catchment.
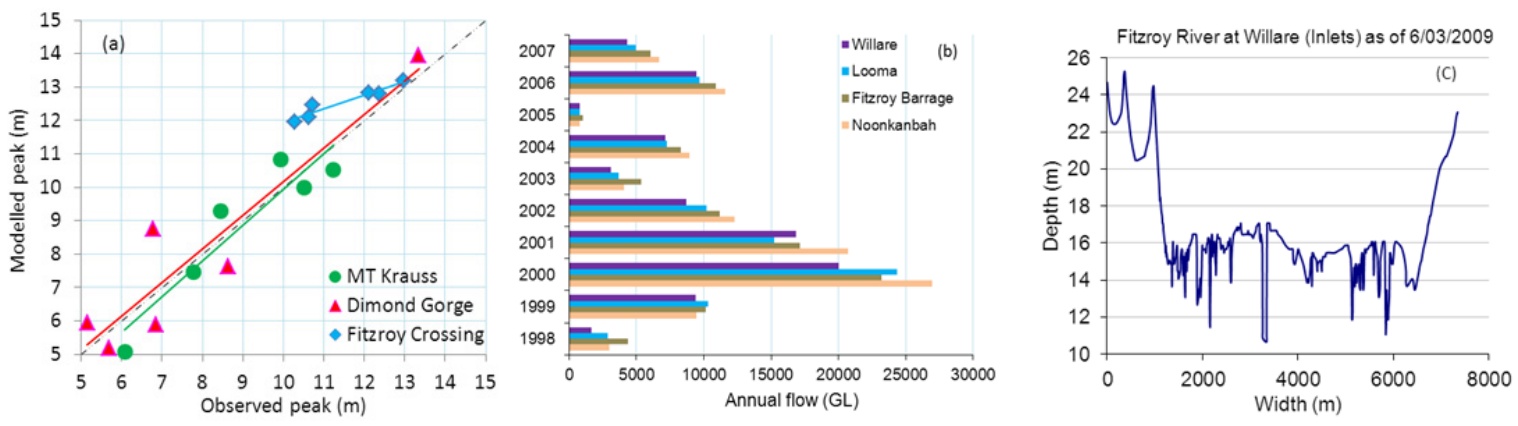

Figure 6. (a) Observed and modelled peaks for the events at three gauging stations; (b) flow anomalies at gauging stations downstream of Fitzroy Crossing; and (c) river cross section at Willare (inlet) with cease to flow level of $10 \mathrm{~m}$ (Data source: Department of Water, WA).

\section{SUMMARY AND CONCLUSIONS}

The LUCICAT model has been tested for its potential to simulate river flow at hourly time step at different gauging stations of Fitzroy River catchment of Western Australia. The model has been successfully tested for 
Islam et al., LUCICAT Model as a river flow forecasting tool: an experiment with Fitzroy River catchment of Western Australia

high flow for understanding its potential as a flood forecasting tool. The Flood module has been calibrated through changing three parameters of the set of calibration parameters obtained from the WBM. The daily WBM and the Flood module calibration performed well for upper half of the catchment, from upstream to Fitzroy Crossing. The braided river system, sparse rainfall network and vary large flood plain at and downstream of Fitzroy Crossing made it difficult to calibrate the daily WBM and hence the Flood module. Thus, the model could be used for simulating river flow from upstream to Fitzroy Crossing. Three hypotheses tested in this experiment to simulate hourly flow are found to be valid. Results suggest that with catchment initial condition from the daily WBM, the Flood module can be run for more than two months to simulate hourly river flow. Hence, the model can be used for continuous river flow forecasting as well as for flood forecasting. Though, Fitzroy is a better gauged catchment in Western Australian context in terms of rainfall and river flow network, the network is very sparse. The sparse rainfall network, braided river system, wide flood plain and very large size of the catchment made it difficult to test the model. Considering these challenges, the model needs to be tested further for some other catchments in Eastern states with better rainfall network and gauges.

\section{ACKNOWLEDGMENTS}

The authors acknowledge the data support provided by Department of Water, Government of Western Australia and Bureau of Meteorology, Government of Australia. This work is part of Doctoral research project of the first author.

\section{REFERENCES}

Ackland, R, Gouweleeuw, B, Ticehurst, C, Thew, P, Raupach, T and Squire, G. (2012). Blending satellite observations to provide automated monitoring of flood events, in Grove, J.R and Rutherford, I.D (eds.) Proceedings of the 6th Australian Stream Management Conference, Managing for Extremes, 6-8 February, 2012, Canberra, Australia, published by the River Basin Management Society, p.p.1 10.

Bari, M. A., \& Smettem, K. R. J. (2003). Development of a salt and water balance model for a large partially cleared catchment. Australian Journal of Water Resources, 7(2), 93-99.

Cloke, H., \& Pappenberger, F. (2009). Ensemble flood forecasting: a review. Journal of Hydrology, 375(3), 613-626.

CSIRO, (2009). Water in the Timor Sea Drainage Division. A report to the Australian Government from the CSIRO Northern Australia Sustainable Yields Project. CSIRO Water for a Healthy Country Flagship, Australia. 508 pp.

Harrington, G.A., Stelfox, L., Gardner, W.P., Davies, P., Doble, R. and Cook, P.G. (2011). Surface water groundwater interactions in the lower Fitzroy River, Western Australia. CSIRO: Water for a Healthy Country National Research Flagship. 54 pp.

Karim, F., Petheram, C., Marvanek, S., Ticehurst, C., Wallace, J. and Gouweleeuw, B. (2011). The use of hydrodynamic modelling and remote sensing to estimate floodplain inundation and flood discharge in a large tropical catchment . In Chan, F., Marinova, D. and Anderssen, R.S. (eds) MODSIM2011, 19th International Congress on Modelling and Simulation. Modelling and Simulation Society of Australia and New Zealand, December 2011, pp. 3796-3802. ISBN: 978-0-9872143-1-7.

Lindsay R.P. and Commander, D.P. (2005). Hydrogeological assessment of the Fitzroy alluvium, Western Australia, Department of Water, Hydrogeological Record Series HG 16. McConnell K, \& O' Connor S. (1997). 40,000 year record of food Plants in the southern Kimberley, Western Australia. Australian Archaeology, 45, 20 - 31.

Miller, W.A., \& Cunge, J.A. (1975). Simplified equations of unsteady flow. In K. Mahmood \& V. Yevjevich (Eds.), Unsteady Flow in Open Channels (Vol. 1, pp. 183-257). Fort Collins, U.S.A.: Water Resources Publications.

Taylor, C. (2000). The flood geomorphology of the Fitzroy River, northwestern Australia: controls and implications for paleoclimate reconstruction, PhD Thesis. University of Western Australia, Centre for Water Research reference ED 1346 CT.

Wohl, E., S. Fuertsch, et al. (1994). "Sedimentary records of late Holocene floods along the Fitzroy and Margaret Rivers, Western Australia." Australian Journal of Earth Sciences, 41(3): 273-280. 